\title{
Linguistic and Sociolinguistic Peculiarities of Family Law Legal Terminology
}

\author{
Ketevan Djachy \\ Faculty of Humanities, University of Sevilla, Spain \\ George Kuparadze \\ Faculty of Humanities, Iv. Javakhishvili State University, Tbilisi, Georgia \\ Lia Rukhiashvili \\ Faculty of Humanities, Iv. Javakhishvili State University, Tbilisi, Georgia
}

\begin{abstract}
This paper concerns a comprehensive study of the Family Law legal terminology and attempts to determine its communicative role and functions in linguistic, sociolinguistic and socio-cultural aspects. Increased contacts between people, societal changes associated with migration processes, and more frequent mixed marriages have led to dynamic socio-cultural values and changes to traditional cultural stereotypes. In this regard, it is interesting to examine and study the marital and family problems in contemporary intercultural space and legal discourse, the sphere that has not been studied yet in terms of comparative analysis in Georgian, English and French languages.
\end{abstract}

Index Terms - family law, marriage, socio-cultural values, legal discourse, legal terminology

\section{INTRODUCTION}

Family law regulates inter-citizen and legal relations in terms of marriage or divorce everywhere, establishes both personal and conjugal rights and obligations; establishes parental rights and responsibilities towards their children and adult children; regulates spouse's post-marital alimony obligations, issues related to children, custody and guardianship. This paper is based on the analysis of Family Law legal terminology in three countries: Georgia, France and the UK.

Family has a long and rich history. Marriage is a union between a man and a woman. It is a voluntary union, a lifelong union and cannot be arbitrarily terminated by any of the parties. These three components are viewed as the basis for identifying marriage as a legal institution. In France and the UK, the Church had a great influence on regulating legal aspects of conjugal relations. In Georgia, during the Soviet period, the function of the Church was diminished. The Church became especially influential in XXI century. Nowadays, almost all couples seek to have their union officially recognized and blessed by the Church.

The legal definitions of "family" itself in all three countries are interesting. In the Georgian Law: the family is a historically established system of relations between a husband and a wife, parents and their children, i.e. a small group of individuals, the members of which are related by blood or marriage, share family life, have mutual responsibility, and the importance of which is conditioned by physical and spiritual needs of the population ${ }^{1}$. French law defines "family" as follows:

C'est un groupement de personnes qui sont reliées entre elles par un engagement de vie commune ou par la filiation. L'engagement de vie commune, c'est le mariage ou le PACS (pacte civil de solidarité introduit par une loi du 15 novembre 1999 et profondément réformé par la loi du 23 juin 2006) ${ }^{2}$ - This is a group of people, who are interconnected with each other through family ties or kinship. The obligation of living together stems from either marriage or Civil Covenant of Solidarity, which was introduced in France on November 15, 1999, and has significantly changed since June 23, 2006. In the UK, in 2008, the Labour government defined 'family' as follows: Families are the bedrock of our society. They nurture children, help to build strength, resilience and moral values in young people, and provide the love and encouragement that helps them lead fulfilling lives. In the UK no legal definition of "family" exists".

After having analysed the literature related to Family Law, we have identified a number of lexemes related to the concepts of family and marriage, such as: civil marriage - mariage civil - bsdmfsmsfm fmळ6o6jzs; marital

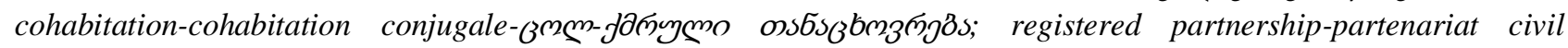

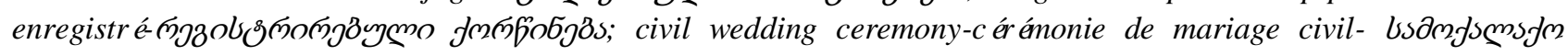

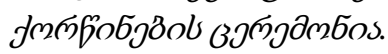

\footnotetext{
${ }^{1}$ http://www.qwelly.com/group/sociology/forum/topics/ojaxis-cneba,(accessed 17/6/2017).

2 http://www.cours-de-droit.net/definition-de-la-famille-a121609182, (accessed 17/6/2017).

3 http://catalogue.pearsoned.co.uk/assets/hip/gb/hip_gb_pearsonhighered/samplechapter/1408255529.pdf, p.1, (accessed15/8/2017).
} 
There are also terms, which denote unregistered partnership, such as: de facto marriage - mariage de facto -

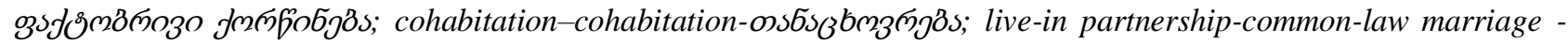

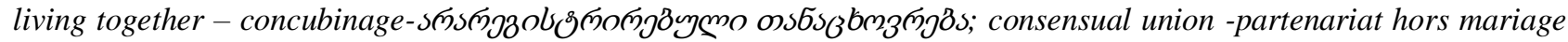

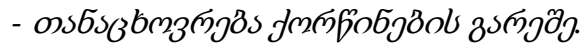

We have identified terms, which denote partnership between the representatives of the same sex, such as: same-sex

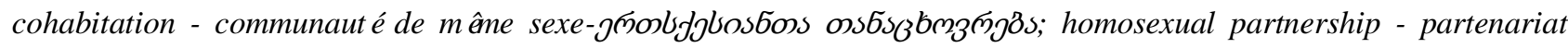

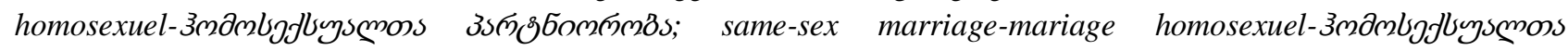
jmळ6објठs.

Hence, social phenomena expressed in the above-mentioned terms clearly show the full picture of modern familybuilding models. As a result of the social changes, new legislative acts are being introduced to regulate the established actual family relationships via bypassing official marriage. Though, it should be noted, that we have identified clear differences as a result of comparing the Family Laws of the three countries. Same-sex marriages are prohibited in Georgia, but are permitted in France though only in the form of civil unions and same-sex couples are not allowed to adopt children. As for the UK, same-sex marriages can be blessed by the church.

Same-sex marriages served as a foundation for the introduction of new terms in the Family Law of France. Nowadays Family and Marriage are being considered separately. New lexical units appear in the legal language, some of which are being introduced through acts and some of them continue to function in common language and in the legal language. First of all, this situation can be explained by the fact that the legislation that reflects family-centred legal relations sometimes fails to catch up with and immediately reflect the changes this field undergoes with respect to societal development.

\section{METHODOLOGY}

Methods that are to be used in this study are a descriptive method, as well as a deductive method, while providing examples chosen from the research material in order to consolidate the arguments and theory developed during the study; as we consider it important to identify and highlight the similarities and differences that exist in the three languages. In addition the methods such as structural-semantic analysis, comparison and contrast; interdisciplinary and intercultural studies are used, which in turn are of great help in developing correct theories and making appropriate conclusions.

\section{ANALYSIS AND RESUlTS}

Terms and expressions used in the Family Law can basically be divided into 4 groups:

1. Terms and expressions which are used to refer to persons in family law. For example: adulteress - femme adultère

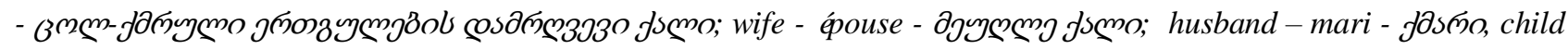
- enfant - Bs3żo, etc.;

2. Terms and expressions which are used to refer to the property relations between spouses. For example: original

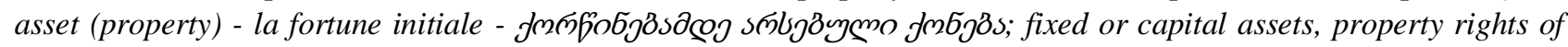

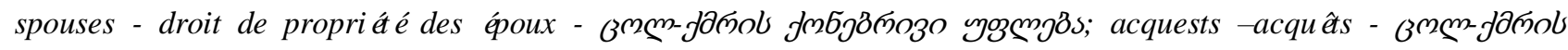
usjnom jmbj8s, etc.;

3. Terms and expressions which belong solely to the field of Family Law. For example: spouses - époux -

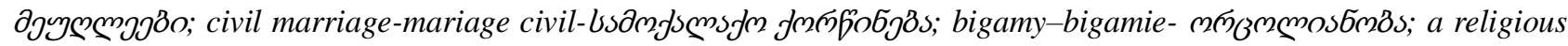

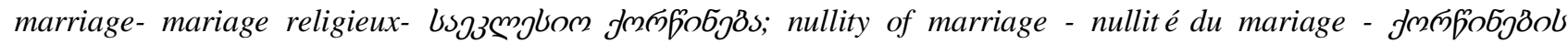

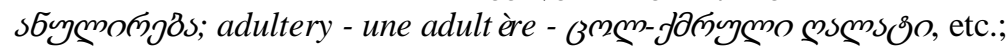

4. Terms and expressions borrowed from different spheres of Law, which have acquired definite meanings in Family Law, in our case these terms belong to Labour Law and Inheritance Law. For example: spouses' obligation to

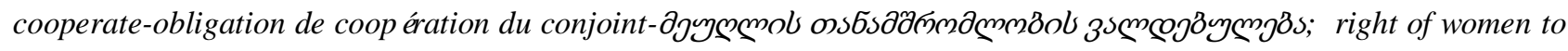

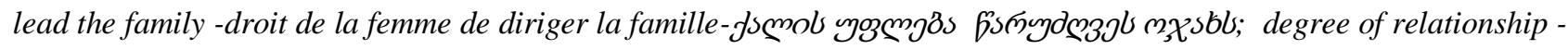
degré de parenté - Gsonglsmóol bsஙobbo, etc.;

Structures of the terms used in the field of Family Law are quite interesting. Relatively older terms use simpler words. Though, terms consisting of two or three words, prepositional phrases used as nouns, as well as structures that use a combination of adjectives and nouns are used in all three languages considered.

Majority of the terms belonging to the field of Family Law and denoting family and family relations are the terms that consist of single words in all three languages considered. Though, we frequently come across compound terms which consist of two or more than two words. The three languages use word formations, affix-based word-formations, compounds or composite nominals, terms using prepositions and adjectives, word families. Examples of root words are:

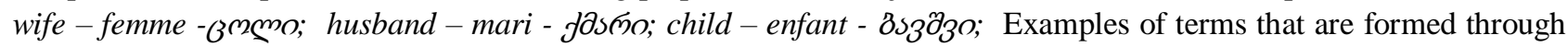

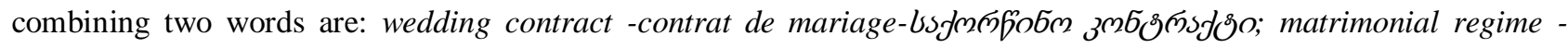




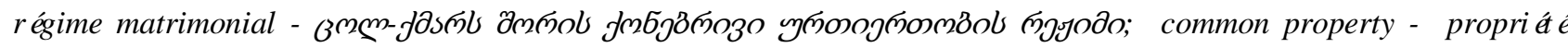

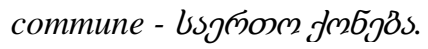

As a result of the analysis conducted by us, we identified some groups of words, which participate in the wordformation process; these groups are listed below:

1. Terms, which contain prepositional phrases used as nouns: for example: sojgombol sposmj8s- recognition of motherhood - reconnaissance de maternité; zs6jm

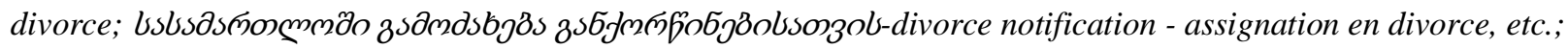

2. Terms, which are formed by combining nouns and adjectives; for example: $8 s_{3} \partial_{3}$ ob sposm

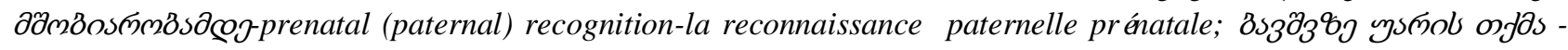

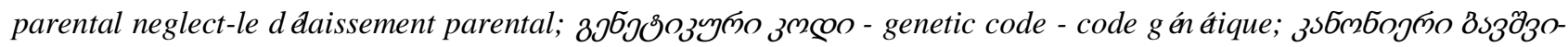

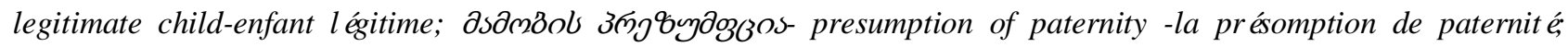

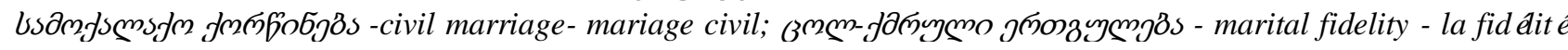
conjugale, etc. English and French terms are much the same, but we cannot say the same when we compare these terms with their Georgian equivalents. A single term, which has the same structure in all the three languages considered, is the term $325 \jmath \triangleleft$ озуюо зм⿻о [genetikuri codi], the reason is that the term in Georgian language is formed using words borrowed from a foreign language.

3. English and French languages have some identical terms, such as: testament - testament; apatride - apatride; divorce - divorce; cohabitation - cohabitation; simple adoption - adoption simple; conception - conception. The term apatride is formed using a word borrowed from a foreign language, therefore, the term in the three languages sound identical.

4. Identical terms with different spelling. Some terms in English and French languages are identical but they are spelled differently and these terms are also pronounced differently; for example: bigamy - bigamie; separation séparation; emancipation-émancipation; lesbian-lesbienne; polygamy - polygamie; testator - testateur; pederasty pédérastie; pederast-pédéraste; incest-inceste; paedophilia-pédophilie; procreation -procréation; adoptive parentsparents adoptifs; putative marriage -mariage putatif; subsequent marriage -mariage subséquent; reconciliation réconciliation; mediation - médiation; adultery - adultère; artificial insemination - insémination artificielle; remarriage - le remariage; the homosexual - l'homosexuel; post-nuptial contract - contrat post-nuptial. In the Georgian language

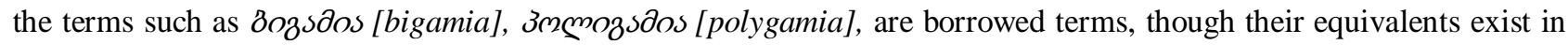

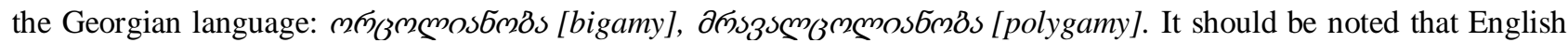
and French terms are almost identical; the difference is revealed in the position of adjectives with regard to nouns. Preposition of adjectives is common in the English language, while post-position of adjectives is common in the French language, which is due to the specificities of the languages compared.

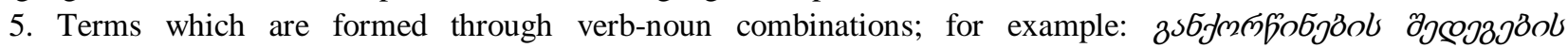

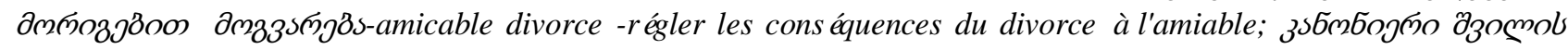
ymmol sposmj8s-possession of the status of a legitimate child-avoir la possession d'état d'enfant légitime; m๓о3つ

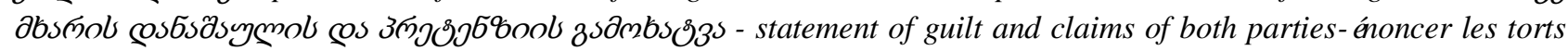

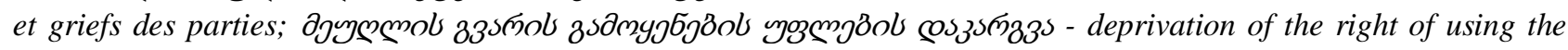

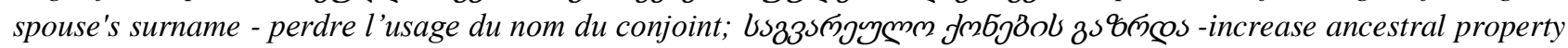
-faire fructifier son patrimoine.

6. Abbreviations, such as: $m g \delta \&-L G B T-L G B T$ in the French and English languages are formed by abbreviating the same words and therefore are absolutely similar, whereas the abbreviation in the Georgian language was borrowed from the English language. We have to highlight the abbreviation - PACS - in the French language, which is the abbreviation that is well-known to everyone in France, and it stands for-Pacte civil de solidarité -a contractual form of civil union between two adults. The abbreviation does not have an equivalent in the Georgian language. The English equivalent of PACS is civil partnership agreements. It should be noted that the abbreviation served as the basis for formation of different adjectives in the French language - pacsé; pacsable; pacsage; as well as for the formation of verbs, such as: pacser; se pacser. It can be said that a word family was formed by adding suffixes to the abbreviation.

7. "False friends of the translator". According to K. Djachy and M. Jashi (2003): "There is not translation but speech. The minimal unit' of translation is a sentence. Word-for-word translations should be avoided. Words that are phonetically similar in two languages are like traps for translators especially for beginners; these words are called false friends of the translator" (Djachy \& Jashi, 2003, p.7). Translators are well aware of the term and the phenomenon or concept it stands for: phonetically similar words that have different meanings in different languages. For example: a French term mariage blanc literally meaning a white marriage is translated as fictitious marriage, whereas in English language there exists a term white wedding, which is translated as the marriage through the Church, when a bride is wearing a white dress.

8. Specific terms. In English and French languages there are terms which are characteristics of only these languages.

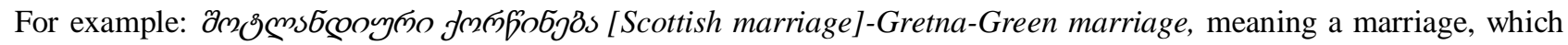


is registered based on the consent of the couple only. Scotland used to be a popular wedding destination for runaway couples from England. This phenomenon is not common among French and can be translated as follows: mariage à Gretna Green, though it might not be quite understandable without further explanations. The term - mariage à l'anglaise - which can be literary translated as English wedding - in the French language means a kind of marriage when a couple live in their own part of the apartment. This term does not have an equivalent in the English language and needs to be explained. One more example of this type of specific terms is: onszolyzsmo fmळ6o6j8s - open marriage - mariage libre. The English equivalent of the term has an adjective open, whereas in the French equivalent, the adjective libre - meaning free - is used. Usage of different adjectives in the term is worth considering, in order to avoid interference.

9. Structures having different syntagmas. There are concepts which are expressed in one word in the English language but use two or more words in the French language. For example: the relationship between family members the filiation - le lien de filiation, though, the single word filiation can be used in the French language as well; best man témoin; affidavit - déclaration sur l'honneur.

10. Words borrowed from the French language: fiancé, fiancée - fiancé, fiancée; in this case the French words maintain not only the French spelling but also the French pronunciation.

It should be noted that Family Law both in the English and French languages have a term which denotes byflyysmy๓о zsбsongyzs [seksualuri ganatleba]: sexual education in the English language and éducation sexuelle in the French language, wich is not taken into account in the Georgian Family Law. We strongly believe that this is a big mistake, as neglecting the issue affects the lives of the society, and particularly the lives of the young generation. Providing young people with the appropriate knowledge in this sphere will form a basis for multiple positive changes in our society.

Thus, the structure and the general characteristics of the Family Law terminology is defined on the one hand by intrasystem factors - determining specific characteristics of common law as well as family law terminology, on the other hand the dynamics of interaction between these characteristics are influenced by extra-linguistic factors associated with developmental peculiarities of socio-cultural situations in the institute of Family and family relations, in the respective societies of the three countries considered. Linguistic literature defines terms as words with strictly defined meanings, which differ from the words in the common language which are characterized by polysemanticism. However, this criterion is controversial in relation to some legal terms, as there are terms which are polysemantic. Interpretation of these terms in the course of intercultural communication depends on a set of linguistic and extra linguistic factors, which can result in different versions of their translation. Searching for adequate ways of translation and considering polysemantic nature of the terms in the legal discourse is of crucial importance in the course of intercultural communication. Analysis conducted in the legal literature demonstrated that one and the same concept can generate different meanings in different contexts, which can impede the proper understanding of a concept. For example: cos6sżymo [danashauli] can have different equivalents in the English and French languages: in the French language: crime, délit, infraction, forfaiture -crimes associated with performance of job responsibilities or obligations; delict, crime, abuse of power, infraction, official malfeasance, malfeasance in office; In order to distinguish between high crimes and misdemeanours, the term cojmofjo [delikti] has been introduced in the Georgian language. Though, the specificity of the term should be considered in the process of translation. In case the variety of the terms did not impede the proper understanding, there would be no need for the standardization of legal terminology. It should also be noted that those synonyms can be found in the family law terminology. There are absolute as well as partial synonyms; and according to the functional characteristics, there are ideographic and stylistic synonyms.

When studying the Family Law terminology in the three languages, from the viewpoint of the intercultural perspectives, special focus is on socio-cultural context associated with the development of the legal relations; for example: usfmळбoбn suszo-marriageable age -âge légal du mariage, l'éligibilité au mariage, âge nubile. Marriageable age in Georgia i.e. the minimum age at which a person - a man or a woman - is allowed by law to marry is 18 years. Though, with the consent of parents a person is allowed to marry at the age of 16. Marriageable age in the UK and in France is 18. In Georgia, even if the parents are against their children's marriage, because of their age, the court may consider granting consent to register a marriage under certain circumstances. There exists an exact equivalent of premarital agreement in the English and French languages: wedding contract - in the English language, and contrat de mariage - in the French language. Premarital agreement is mandatory in the UK and France. In Georgia, future spouses are not required to sign this kind of agreement but they can sign an agreement, which regulates their property rights and liabilities during the marriage and in case of the divorce. It should be noted that the practice of signing a wedding contract is not common in Georgia and as a result many people, particularly women are insecure in case of divorce and do not receive any property if the couple do not have children.

\section{DisCUSSIONS AND CONCLUSIONS}

Multiple amendments have been made to the civil codes, inter alia to the Family Laws of the three countries since their introduction. The Civil Code of Georgia is the one of the three which has been amended not long ago. These amendments have been reflected in the language of legal documents. Changes of public opinion and of the attitude of 
Family Law towards this or that issue are inevitably followed by changes in the language concerned. Studying cultural and historical changes in the course of the development of a legal language and diachronic-comparative or contrastive analysis of legal texts allow us to identify and describe the linguistic facts of Family Law of all three countries, which reveal the interrelation between linguistic and socio-cultural aspects in the course of studying legal terminology. We would like to substantiate the above mentioned based on the two examples given below:

1. Axiological aspect of the reflection of the legal norms in the language. Social norms which include Family Law norms, function as pragmatic attitudes, the nonexistence of these norms makes it impossible to explain social values and to understand the impact of certain cultural-historical connotations on the means of legal norms. English term illegitimate child, and its equivalent in the French language - enfant illégitime - can serve as an example to substantiate the above mentioned. Georgian Law does not discriminate between children in this respect, which makes the Family Law of Georgia different from the Family Laws of France and the UK.

2. Explaining the development of family relations in the legal language. The term father's care has been replaced by the term parent's care.

In France, in 1804, Napoleon developed a concept, according to which authority in a family belonged to fathers, as they were supposed to be household heads, assuming the responsibilities and functions of authority figures for the household members. A husband was an authority figure in the family, responsible for protecting his wife and a wife was supposed to obey her husband. A family should have a house and the wife was required to live together with her husband. The Civil Code reflected the habits established in Paris. Certain though limited progress was detectable in the Civil Code of France in this regard: daughters were obliged to obey their fathers exactly as it was envisaged in the Roman law $^{4}$. Today, both parents care about their children. They share their responsibilities for their children's wellbeing. Parental duties include upbringing their children and providing them with the opportunities to receive education; though it should be noted, that children have some responsibilities as well; their responsibilities include caring about their parents, which is not the case quite often. A good example of it is the developments in France in 2003 and 2015. Heat waves killed too many elderly people; they died of dehydration and the majority of them had children of their own. This fact remains as a shameful fact in the history of France.

Family relations have undergone certain changes in the UK as well. Women are no longer dependent on their families. Some analysts believe that since the beginning of the 21 st century we have witnessed fundamental changes in the family relations. People tend to get married at older ages than they used to. The Number of marriages has declined. The number of people living together as a couple without being married has increased. The number of divorces has risen dramatically. The number of single parent families has increased. Birth rate has been declining for years. More and more people over 18 are more likely to be living with their parents. In 2006, 58\% of men and $39 \%$ of women aged 20-24 were still living with their parents. According to the 2009 statistics, more than 7 million people in the UK (12\% of the UK total population) live in single-person households 5 .

Georgian Law does not discriminate between the families where children live with both parents and so called singleparent families, where children live with only one parent. From a legal point of view, single parent families appear as a result of unmarried women giving birth to children, as a result of a divorced, when children live with one of the parents, or when children are brought up by widows or widowers. Besides, children and parents living together are considered as a single household, but if a child does not live with one of his/her parents (in case the parent is alive and the parenthood has been legally established), the child and the parent are not considered as members of a single household, instead their relations are that of kinship type and the patterns of relations characterized by a whole set of rights and obligations (alimony, inheritance, etc.) arising out of this kinship prevail between them (Chikvashvili, 2004, p.53).

After having discussed the developments, the terminology and terms that are used to denote the above mentioned

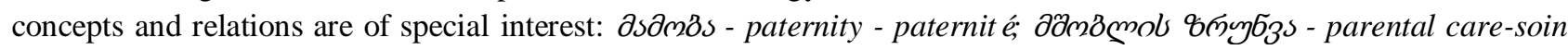

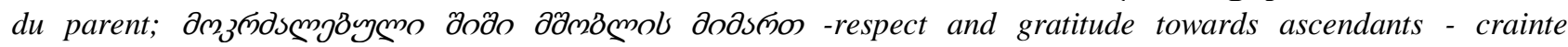

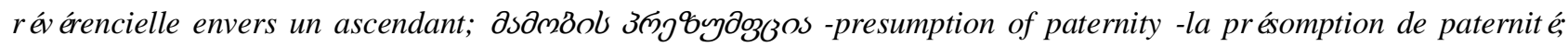

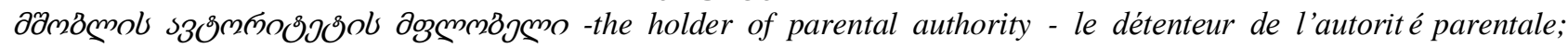

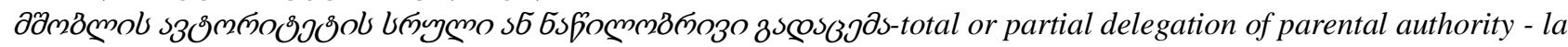

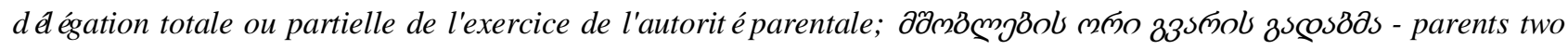

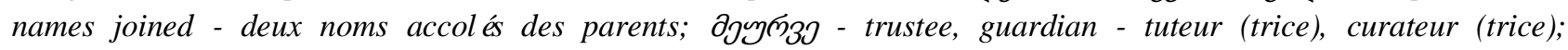

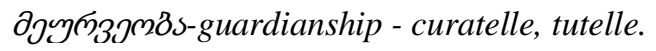

Legal terminology of Family Law in spoken and written languages has the function characteristic of general terminology. The phrases used in all three languages denote certain concepts. From this point of view, they have nominative function. Though, it should be noted that the function is characteristic of majority of words in general language.

In this regard, V. Danilenko (1977) and R. Kobrin (1969) suggest that it is more appropriate to talk about a common nominative-definitive function of terms (Danilenko, 1977, p.7-8; Kobrin, 1969, p. 63). The definitive function of terms

\footnotetext{
${ }^{4}$ http://www.cours-de-droit.net/histoire-du-droit-de-la-famille-c27647228, (accessed 11/10/2017).

5 http://catalogue.pearsoned.co.uk/assets/hip/gb/hip_gb_pearsonhighered/samplechapter/1408255529.pdf, p.51, (accessed 28/10/2017).
} 
allow us to distinguish one object from another, as a definition helps define the scientific concept, in spite of the fact that some terms, including Family Law terms, do not have a single definition. A good example of this is the definition of Family.

The reach of the concept of family depends on the legal basis the term is used in, as well as on the attitude of certain lawyers towards the issue concerned; moreover, because same-sex cohabitation and marriage, in the UK and France, have completely changed the definition of the term 'family'.

The situation in Georgia is different and the term family is still understood and defined in its original, traditional sense, i.e. a typical modern Georgian family is based on a marriage involving a romantic relationship and equality between family members, which guarantee the strength of a Georgian family. This attitude stems from a set of historically established universal elements characteristic of a Georgian family, such as: a serious approach to the issue of starting a family; close, multilateral and traditional ties between parents and their children and other members of the family; a strong sense of kinship; a special care for the young generation. Marriage is a union between a man and a woman, i.e. between representatives of different sexes. Until recently the definition raised no questions. Sexual relations between persons of the same sex - as an element of human culture - have been known from ancient times; though, legal recognition of unions between individuals representing the same sex is a recent phenomenon, which has become increasingly common during the past few decades in a number of countries, such as: Denmark, Norway, Sweden, France. The issue is a subject of fierce discussion in scientific literature and in many countries, as these countries' legislations do not recognize legitimacy of these unions and are against introduction of legislation allowing same-sex marriage (Chikvashvili, 2004, p. 50).

A term has a significative function. The significative function of a term means that it is capable of expressing a concept. We think that not all terms are capable of expressing concepts equally. It will be more appropriate to talk about the function of a term, since there is a special concept behind every term. If a term expresses a scientific concept, it should accurately determine its boundaries. Thus the definitive function of the term is raised again.

S. Grinev (1993) suggests identification of the gnoseological function of the term, which is of complex nature. The gnoseological function, first of all, implies heuristic function, a function of acquiring new knowledge, methodological, diagnostic function (Grinev, 1993, p.216). The above mentioned example indicates that, apart from legitimate family relations, there is a new form of family relationship that is formed on the basis of relations between a man and a woman, which is stable and is a kind of marriage in its essence. The fact that the term has been entered in the vocabularies of the English and French languages demonstrates that such form of marriage is allowed in the UK and France. Family Law has been developed and enriched this way. A systemized function of the term is that it belongs to the sphere of Family Law.

It can be assumed that lawmakers in Great Britain and France take into account the existing situation and use different terms to express unregistered unions. For example: cohabitation, marital cohabitation, conjugal cohabitation, common-law marriage, non-marital relationship, extra-marital cohabitation, cohabiting union, consensual unioncohabitation, union matrimoniale, régime conjugal, communauté conjugale, concubinage, mariage en détrempe, mariage du côté gauche, union de fait, partenariat non matrimonial, situation familiale extra-conjugale, communauté

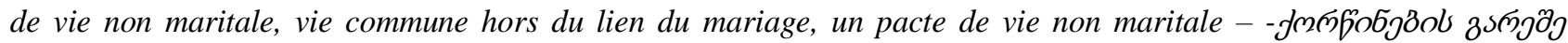
osбsзbmзбодs-all meaning relationship outside marriage. As we can see, sets of synonyms are used in both English and French languages of justice to express the concept.

It should be noted that the gnoseological function implies cognition, which formally defines the level of knowledge on a given object, subject or event. Certain level of knowledge can be found in an encyclopaedic dictionary. The gnoseological function implies a transfer of didactic and informative functions of knowledge. The didactic function of a term implies that the term can be used while teaching the law that deals with family matters and domestic relations.

The informative function implies the expression of the content of definition using relatively brief terms. When the issue of cohabitation is raised, there is an attempt to express the information using one of the abovementioned terms. In

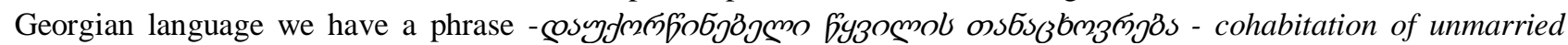
couples. It is not quite a common form of cohabitation in Georgian reality, though it should be noted that such form of cohabitation has become more common among young people in recent times. The concept which in Georgian language is expressed by a single term can be expressed by a whole group of terms in the English and French languages.

The term zm3szossosos [cohabitacia] is used in Georgian language. The French term - cohabitation - is a word borrowed from the English language. In this respect we would like to quote Marianne Lederer (2006), saying that “According to the Webster's Dictionary, cohabitation means 'living together as a husband and a wife'. In March 1993, BBC interpreted this term literally and used it to refer to the President of France François Mitterrand and Prime Minister Édouard Balladur: "The problem is the power-sharing, which the French call cohabitation, since for them everything partakes in the pleasures of the flesh, even in politics"[...]. It is the fact that the British accuse the French of being too fond of love affairs, but using the French term cohabitation in its English meaning was an exaggeration (Lederer, 2006, p. 214-215).

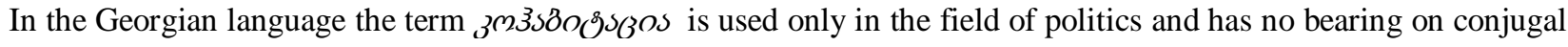
relations or on cohabitation of unmarried couples. The problem related to the description of a term, which helps give cultural information, is quite common and well-known. E. Vereshchagin and V. Kostomarov (2005) were the first 
scientists to give a theoretically founded thesis on the background characteristics of the terminological vocabulary (Vereshchagin \& Kostomarov, 2005, p.94-97). They suggested that the category "lexical concept" and "lexical background" refers to not only the common language, but also to terms.

As a result of the analysis of terms, they found out that majority of terms form part of the common language and therefore, they behave like normal words (Vereshchagin, Kostomarov, 2005, p. 95). In order to further elaborate the thesis we developed a method of analysis of the background characteristics of the legal terminology.

The term fmø French equivalent mariage, taken from Family Law, can be analysed as an example. The term implies a concept that is recognized by the Law as well as by the Church and means a voluntary relationship between a man and a woman. Some

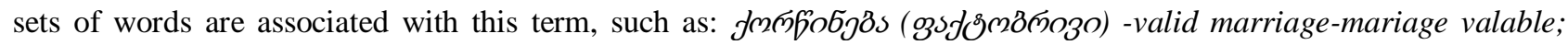

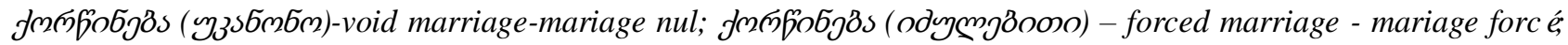

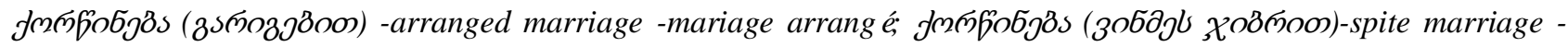

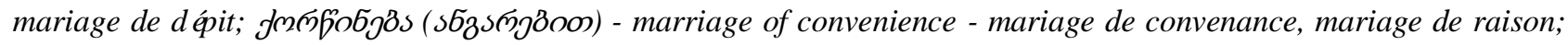

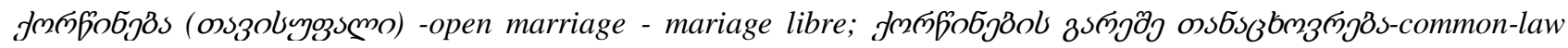
marriage - concubinage, mariage en détrempe, mariage du côté gauche.

Thus, the word marriage has been entered as a common word into the general language of all the three languages. When used as part of the general language, the term does not have the characteristics which are important for a marriage from a legal point of view (temporary characterization, a basis for marriage - marriage contract and marriage form and procedures).

We have already explained the concept behind the term marriage from a legal point of view. Apart from differences, there are some important similarities between the word and the term, which implies the legally recognized relationship between a woman and a man. Therefore, the word and the term are of equal value from the viewpoint of semantics: both have a concept and a background; though the content and background of the word significantly differs from the content and background of the term (Vereshchagin \& Kostomarov, 2005, p. 96).

Terms are divided into two lexicological groups according to their origin: terminologized (the creation of terms by taking general language words already in existence in the language and matching them to source terms denoting foreign concepts) and of terminological origin (terms that enter the general language as words). Terminologized vocabulary units, as a rule, maintain their vital inner form and their figurativeness, as well as the cultural and historical associations characteristic to the original word (Vereshchagin \& Kostomarov, 2005, p. 96).

For example the English and French languages use an identical legal terms - filiation - filiation - to express or denote kin relations. In the French language there is another term parenté, which maintains its association with neutral usage in the general language. For example: la filiation des sens des mots — development of the meanings of words; la filiation des idées - development of ideas; la filiation des événements - sequence of events; filiations from a common stock - a branch of a particular language; filiation - branch, department.

Vocabulary of terminological origin also has a national and cultural semantics. Certainly, most terms developed within a certain field of science do not exceed the boundaries of that particular field. Despite this fact, growing level of education of the native speakers of a language facilitated the introduction of this vocabulary into the general language; so that the words maintain their "terminological" semantics and develop secondary lexical meanings (Vereshchagin \& Kostomarov, 2005, p. 96).

Family Law in all three languages studied is characterized by a particular feature, namely, while comparing and contrasting legal terminology of the three languages, we came across lacunae, which appear in a language because no equivalents of them can be found in this language. Lacunae are the words or collocations, which cannot be translated into other languages and expressed with a single word or a collocation. Lacunae are translated using free word combinations or explanations. Ethnopsychology (1988) identifies the following types of lacunae (Ethnopsychology, 1988, p.125):

- Linguistic (lexical, stylistic and grammatical). This type of lacunae can be either absolute or partial;

- Cultural lacunae (ethnographic, psychological, associated with a behaviour, i.e., behavioural and kinetic);

- Textual lacunae.

The most numerous and diverse of all linguistic lacunae are lexical lacunae. There is virtually no word, which, in other languages, has as many meanings as in the language it has derived from, or can collocate with as many words as in the language it has derived from. The words characterising the English and French lifestyle represent absolute lacunae in the Georgian language. They can be expressed by free collocations or explanations; otherwise they cannot be correctly understood.

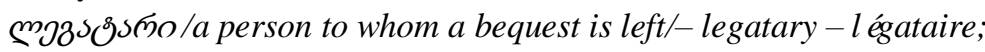

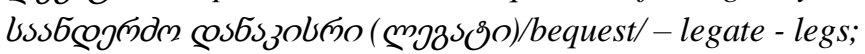

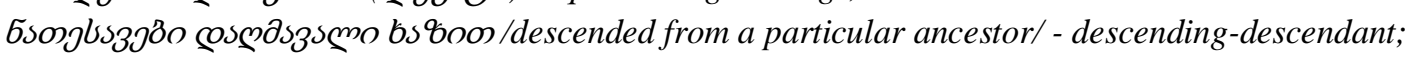

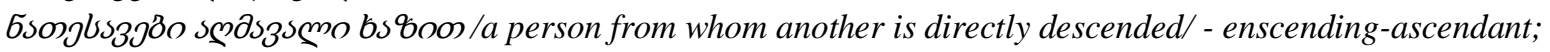

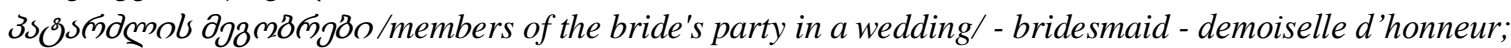

५s 


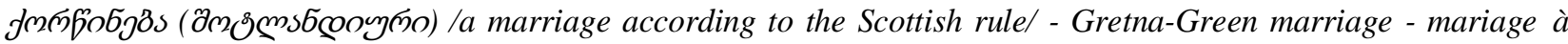
Gretna-Green

Jmmfobj8s (obzmobyms(o) /a marriage according to the English rule, when a couple live in their own part of the apartment/ - mariage à l'anglaise - the term does not have an English equivalent.

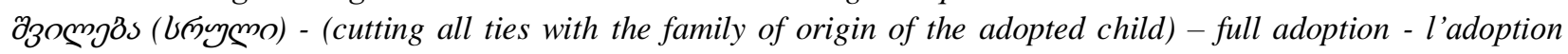
plénière.
\end{abstract}

Cultural lacunae are very interesting. In this respect we would like to quote Marianne Lederer (2006), saying that problems related to culture are most frequently cited as the difficulties associated with translation. Certain objects or concepts associated with a particular culture might not have lexical equivalents in the community of a target language. Words related to cloths, food, religious or traditional habits characteristic of a particular culture might not be understandable for the readers of the translated text. The problem is not only finding an appropriate equivalent of a term used in the source language when translating it into the target language, but also knowing how to interpret the implicit idea or concept, the term has in the source language.

Thus, it can be argued that a particular language incapable of depicting the facts and concepts of the given reality, using its vocabulary and structures, can prove to be incapable of interpreting the implicit ideas. That might have been true in case translation had been transcoding ${ }^{6}$. While translating texts it is not the case. The principle of the theory of translation is that a translator should be aware of and have a good knowledge of the "culture" of the people speaking the source language. A bilingual translator represents two cultures, meaning that he/she has a very good knowledge and understanding of the two cultures involved. He/she is able to perceive and understand the reality described in the texts written in two different languages, using his/her own linguistic knowledge and his/her knowledge of objective reality. $\mathrm{He} / \mathrm{she}$ has the ability to perceive, describe and make others understand a reality not familiar to them. If human had not had an ability to perceive unknown to him/her reality, we would have been deprived of the possibility to acquire broader knowledge which goes beyond the boundaries of acquiring the knowledge of a language and of a meaning.

Any reader can understand foreign literary works, which highlights the universality of a human being. When a literary work describes some habits or traditions, only a few readers can be expected to have the appropriate knowledge to understand the facts related to a foreign culture when the facts are interpreted word-to-word. Finding solutions to the problem related to providing the readers with a minimal but sufficient additional knowledge of the foreign culture, enabling them to gain access to understanding a "foreign" reality, lies with the translator. There is no universal solution to the problem of translating a cultural phenomenon from a source language into a target language. In this case, the relevant solution can be found depending on the function of the excerpt to be translated [...] (Lederer, 2006, p.177-179).

In conclusion, the structure of the general characteristics of the Family Law terminology depends on the internal factors of the system, which define both general and specific characteristics of Family Law terminology, on the one hand, and the dynamics of the interaction between these characteristics, which is due to the influence of the extralinguistic factors, associated with one another through peculiarities of the development of the socio-cultural environment of family institution and family relations in all three countries, on the other hand. While studying the Family Law terminology of the three languages, socio-cultural context for the development of legal relations plays a special role in the research of the Family Law terminology, from the intercultural perspective. Functional analysis in Family Law terminology of all three countries revealed the existence of nominative, definitional, significative and gnoseological functions of legal terms. While describing peculiarities of the legal terminologies of the three countries, we identified major patterns of the formation of terms; such as: explicit derivation and implicit derivation, abbreviations, word families, word groups.

Research in the paradigmatic relationship in legal terminology of all three languages enables us to conclude that synonymy, antonymy and polysemy are the phenomena characteristic of Family Laws of all three languages. There are loan terms in the Georgian language. It should be noted that most of the terms in all three languages - about $90 \%$ of the terms - are of native origin, and only $10 \%$ of the terms are derived from Latin terms, though virtually all of these Latin terms have equivalents in these languages. In the structure of paradigmatic relationship, synonymy can be described either based on the degree of synonymy, i.e. absolute and partial synonyms, or based on the functional characteristics, i.e. ideographic and stylistic synonyms.

Identifying linguistic principles of legal texts, while considering the dynamics of social changes in the legal language, the findings of the studies in the cultural-historical perspectives of the development of the legal language and of comparative analysis of the legal texts, allows to identify and describe linguistic facts characteristic of Family Laws of all three countries, which demonstrate links between the linguistic and socio-cultural aspects in the course of studying legal terminology.

\title{
REFERENCES
}

[1] Chikvashvili, Sh. (2004). Saojakho samartali. [Family Law], Tbilisi: Meridiani.

[2] Danilenko, V. P. (1977). Ruskaya Terminologiya, [Russian Terminology]. Moscow: Nauka.

[3] Djachy, K.\& Jashi, M. (2003). Targmnis teknika [The technique of translation]. Tbilisi: Lingua Plus.

${ }^{6}$ Transcoding means substituting words and phrases of the source language by corresponding expressions of the target language. 
[4] Etnopsikholingvistika [Ethno psycholinguistic]. (1988). ed., Y. A. Sorokin, Moscow: Visšaya Škola.

[5] Family Law, Terms and Definitions. (2008). second edition, http://publiclegalinfo.com/wp-content/uploads/2012/03/FamilyLaw-Terms-and-Definitions-second-edition.pdf ,(accessed on 27/10/2017).

[6] Grinev, S. V. (1993). Vvedeniye v terminovedeniye [Introduction to Terminology]. Moscow: Moscow Lyceum.

[7] Kobrin, R. Y. (1969). Opit lingvisticheskogo analiza terminologii [Experience in linguistic analysis of terminology], Summary of Ph.D. thesis, Gorki.

[8] Lederer, M. (2006). La traduction aujourd'hui, le modèle interprétatif, nouvelle édition, [Translation today, the interpretative model, new edition], Caen: lettres modernes minard.

[9] Vereshchagin, E. \& M. Kostomarov, V. G. (2005). Yazik i kultura. Tri lingvostranovedcheskie koncepcii: leksicheskogo fona, reche-povedencheskikh taktik i sapientemi [Language and culture. Three cultural concepts: lexical background, behavioural tactics and Sapience], ed. and epilogue by academician Y. S. Stepanov. Moscow: Indrik.

[10] What is Family Law

(2010), http://catalogue.pearsoned.co.uk/assets/hip/gb/hip_gb_pearsonhighered/samplechapter/1408255529.pdf, (accessed 15/8/2017).

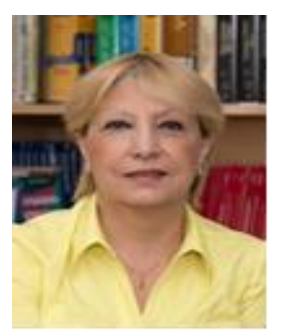

Ketevan Djachy was born in Tbilisi, Georgia on 27 August 1956. In 1973 she has obtained the Certificate of Secondary education, honored with Gold Medal, at school N 23. In 1978 she was graduated with Bachelor degree in French Language of the Roman-German faculty at M. Lomonosov University of Moscow. In 1990 has defended Doctoral Thesis and has obtained the Diploma of PHD in comparative linguistics, Iv. Javakhishvili State University of Tbilisi. In 1996 has obtained the Certificate of a Docent. In 2002 has defended Thesis of Habilitation and has obtained the Diploma of a Doctor of Sciences in Romance philology, in Iv. Javakhishvili State University of Tbilisi.

She was Teaching Assistant in Ilia Chavchvadze State Institute of Foreign Languages of Tbilisi. In 1996 she has conferred the scientific-pedagogical title of the Docent. From 2002 to 2006 she was Professor FLE/LEA at the Branch of Paul Valéry State University of Montpellier III of Ilia State University of Tbilisi. Since 2016, she is member of Research group HUM: 978 Teaching and application of languages in Literature, Language and Translation at University of Seville, Spain. Since 2006 she was Full Professor of Ilia State University of Tbilisi. She had participated in 21 International Conferences. She had obtained beneficiary grants of individual mobility 6 times. In 2000, she took the 3th place in Competition among Universities' Professors, held by Embassy of France and was awarded with prize. She has organized two professional training projects on translation (for teachers of high educational institutions in capital and 3 regions) in 2014 and 2016 funded by the French Embassy in Georgia. In 1997, she has participated in three broadcasts on the "France Culture" and two TV broadcasts on "France 2" in Paris.

Since 1994 she is Simultaneous Interpreter (French-Georgian-French, Russian-French) and has participated in 53 International Conferences, organized by International organizations, as BSEC, PABSEC, UNESCO, TAD, NATO, Council of Europe, dedicated to political, economical, law, social issues. Author of 19 books and 95 articles:

1. A Contrastive Study of the Semantic Content of the Adjectives in French and Georgian Languages, in Theory and Practice in Language Studies, Vol. 6, No 1, pp. 11-20, 2016.

2. L'évolution de la terminologie économique géorgienne au sein du système bancaire entre 2010-2015, in Revista Académica liLETRAd, Sevilla : Fénix Editora, Vol. 2. p. 415-422, 2016.

3. Traduire le droit civil français en géorgien: texte et sens, Actes du Colloque, in Revista Académica liLETRAD, Sevilla: Fénix Editora, pp.385-393, 2015.

Prof. Djachy is Member of scientific and editorial board of International Iranian Review "Le Linguiste", Polish International review E-Scripta Romanica and Spanish International review Revista Académica liLETRAD. Member of International Organizations (Since 2012-0EP, CIEF, 2006-Group LTT of AUF). She has been Member of Doctorate Board (2014, 2010, 2009Baku, 2006-Paris IV-Sorbonne) at the international level and at the national level 46 times. In 2011 she was awarded Knight of the Order of Academic Palms, by Mr. Eric Fournier, Ambassador of France in Georgia, for services rendered to French culture.

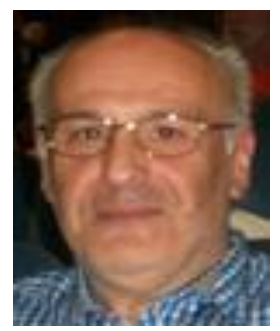

George Kuparadze was born in Tbilisi, Georgia on July 14, 1961. In 1978 he obtained the Certificate of Secondary education, at school N 140. In 1985, he graduated Tbilisi State University with master's degree in the English Philology at the faculty of West-European Languages and Literature with hounor. In 1995 defended Doctoral Thesis and has obtained the Diploma of PHD in the history of linguistics, at Arnold Chikobava Institute of Linguistics. In 1997 obtained the Certificate of Docent.

George Kuparadze, associate Professor in the Department of English Philology at Tbilisi State University has been teaching ESP and EAP for over thirty years at several schools of the University; The author of numerous articles in Phonology, Linguistics, Sociolinguistics, ESP teaching Methodology and of a full length study titled " The Development of Intonation in Infants;"; Participant of various international projects in EFL and ESL in the USA and the UK organized by Georgetown and Cambridge Universities. A visiting scholar at St. Michael's College, A visiting professor at Tuscia University (Italy). The member of ETAG in Georgia. The graduate of two e-course programmes conducted by ETTO and OU (Oregon University). Academic interests: Linguistic Models of Translation, Lexical Equivalence, Adequacy of Translation, Functional theory of Translation, History of Translation Studies, Sociolinguistic and Intercultural Aspects of Professional Language Development.

1. Kuparadze, G. \& al., Contrastive Phonetics of Languages. On the material of Georgian, English, German and French Languages. Tbilisi: Meridiani, 2017.

2. Kuparadze, G. Phonetic and Lexical Stylistic Devices in the Newspaper Headlines, Revista académica liLETRAd, 2 (2016). pp. 513-518, Sevilla: Fénix Editora, ISSN 2444-7439, 2016. 
3. Kuparadze, G. \& Kvantaliani, M. Sociolinguistic Aspects of Professional Language Teaching, Journal of Teaching and Education, Vol.1, N.5, pp.89-101, ISSN: 2165-6266:89-101 (2012), UniversityPublications.net, 2012, http://www.universitypublications.net/jte/0105/html/PAR203.xml

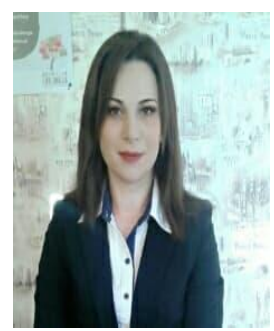

Lia Rukhiashvili was born in Dusheti, Georgia on 29 June 1981. In 1998 she obtained Certificate of Secondary education, at Jinvali Public school. In 2003 she was graduated with Bachelor's degree in the English Philology, faculty of pedagog at Ilia Chavchavadze State Univerity of Languages and Culture (English Department). In 2005 she was granted with a Certificate of Interpreter/Translator of the English language at Tbilisi I. Chavchavadze State University Of Languages and Culture, Department of simultaneous Interpretation. In 2014 she obtained the degree of master of education administration at Ilia State University. At present she studies at I. Javakhishvili Tbilisi State University, for a doctoral degree, faculty of English philology.

She was teaching in "Many- Sided Secondary School-Licee "AISI" (English Teacher) 2003-2006.

She was teaching in "English-Spanish School licee AIA GESS" (English Teacher, 2005-2007).

She was teaching in "Chaglar International School "(English Teacher, 2013-2015)

She has been teaching English at "Georgian-American High School" since 2015.

In 2013 she passed through the 16 hour in service training course First Certificate English (FCE/B2). In 2014, October, 4-English language teaching training, in 2014, November, 22-Class managing training.

1. Legal terms and Professional Communication, Scripta manent, No 3, pp.32-38, 2017.

2. Djachy, K., Rukhiashvili, L.,La spécificité de la terminologie du droit de la famille dans les textes juridiques anglais, français et géorgien, in Revista Académica liLETRAd, Sevilla: Fénix Editora, be in press. 